\title{
Mechanisms of laser nanoparticle-based techniques for gene transfection-a calculation study
}

\author{
Chengbo Liu $\cdot$ Zheng Li $\cdot$ Zhenxi Zhang
}

Published online: 11 June 2009

(C) Springer Science + Business Media B.V. 2009

\section{Erratum to: Journal of Biological Physics DOI 10.1007/s10867-009-9138-z}

In the Acknowledgement part of this article:

This work was supported by the National Nature Science Foundation of China (Grant No. 50877056).

The Grant No. was incorrectly written. It should be changed to 60878056 .

The online version of the original article can be found at: http://dx.doi.org/10.1007/s10867-009-9138-z.

C. Liu $\cdot$ Z. Li $\cdot$ Z. Zhang $(\varangle)$

Key laboratory of Biomedical Information Engineering of Education Ministry, Institute of Biomedical Analytical Technology and Instrumentation, School of Life Science and Technology, Xi'an Jiaotong University, No. 28 Xianning West Road, Xi'an 710049, China e-mail: sandycbliu@gmail.com 